\title{
Association of Prolong PR and QTC Intervals with Cardiovascular Events and Mortality: The Isfahan Cohort Study
}

\author{
Mohammad Kermani-Alghoraishi ${ }^{1,2}$, Hamidreza Roohafza ${ }^{2,3}$, Rahil Ghahramani ${ }^{3}$, Mohammad \\ Talaei $^{4}$, Nizal Sarrafzadegan ${ }^{1}$ and Masoumeh Sadeghi ${ }^{3 *}$ \\ ${ }^{1}$ Isfahan Cardiovascular Research Center, Cardiovascular Research Institute, Isfahan University of Medical Sciences, Isfahan, \\ Iran
}

${ }^{2}$ Interventional Cardiology Research Center, Cardiovascular Research Institute, Isfahan University of Medical Sciences, Isfahan, Iran

${ }^{3}$ Cardiac Rehabilitation Research Center, Cardiovascular Research Institute, Isfahan University of Medical Sciences, Isfahan, Iran

${ }^{4}$ Institute of Population Health Sciences, Barts and the London School of Medicine, Queen Mary University of London, United Kingdom

*Corresponding author: Masoumeh Sadeghi, Cardiac Rehabilitation Research Center, Cardiovascular Research Institute, Isfahan

University of Medical Sciences, Isfahan, Iran. PO Box 8158388994

\section{ARTICLE INFO}

Received: 慧 August 11, 2020

Published: 幽 August 27, 2020

Citation: Mohammad Kermani-Alghoraishi, Hamidreza Roohafza, Rahil Ghahramani, Mohammad Talaei, Nizal Sarrafzadegan, Masoumeh Sadeghi. Association of Prolong PR and QTC Intervals with Cardiovascular Events and Mortality: The Isfahan Cohort Study. Biomed J Sci \& Tech Res 29(5)-2020. BJSTR. MS.ID.004858.

Keywords: PR Interval; Heart Rate-Corrected Qt Interval; Cardiovascular Events; Cardiovascular Mortality

\section{ABSTRACT}

This study aimed to assess PR interval and heart rate-corrected QT (QTC) interval prolongation with cardiovascular events (CVEs) and mortality in Iranian adult population. It is a nested case-control study within the Isfahan Cohort Study (ICS). The ICS is an ongoing longitudinal population based study of 6504 adults aged 35 and older and without history of CVEs. PR and QTC interval was assessed with baseline electrocardiogram. CVEs and mortality defined as fatal and non-fatal acute myocardial infarction and stroke, unstable angina and Sudden Cardiac Death (SCD). The odds ratio was calculated by conditional logistic regression. Totally 432 subjects with CVEs and 394 participants free of CVEs in the control group were included in the analysis. There was not association between prolonged PR interval and CVEs, SCD and cardiovascular mortality in crude and all adjusted models. The same results were seen in prolonged QTC interval and CVEs and SCD; but there was significant relationship between prolonged QTC interval and cardiovascular mortality in crude model, 2.98 (95\% CI: 1.16-7.66, P = 0.023). However, in adjusted models there was no significant difference. In conclusion, prolonged PR and QTC intervals were not associated with an increased risk of CVEs and mortality in Iranian adult.

Abbreviations: ECG: Electrocardiogram; CVEs: Cardiovascular Events; CVD: Cardiovascular Diseases; SCD: Sudden Cardiac Death; ICS: Isfahan Cohort Study; IHD: Ischemic Heart Diseases; AMI: Acute Myocardial Infarction; UA: Unstable Angina; AHA: American Heart Association; ACC: American College of Cardiology; SPSS: Statistical Program for Social Sciences Software; DM: Diabetes Mellitus; HTN: Hypertension; AF: Atrial Fibrillation 


\section{Introduction}

As has been well established, the resting Electrocardiogram (ECG) findings provide valuable diagnostic and prognostic information for the occurrence of Cardiovascular Events (CVEs), independent of traditional risk factors. Abnormal QRS complex and ST-T segment changes are the most common finding that predictive Cardiovascular Diseases (CVD) and mortality [1-3]. However, the predictive role of some finding like heart-rate corrected QT (QTC) and especially PR interval are still not fully understood. Despite the benign nature of prolonged PR interval and contrary to previous studies; prolongation of the PR interval was also associated with mortality [4,5]. As we know, prolonged QTC interval (genetically or acquired) predisposes to malignant Ventricular Arrhythmias (VT) and Sudden Cardiac Death (SCD) [6,7]; although different results have been reported in various studies regarding its association with CVD or mortality [8-10]. On the other hand, some studies reported the differences by communities and race/ethnic in the prevalence of numerous ECG findings [11,12]. To our knowledge there has not been any records regarding the association of PR and QTC interval and CVD in Iranian adults. Therefore, the purpose of this study is to explore the association of PR and QTC interval prolongation with CVEs and mortality in adults who participated in the Isfahan Cohort Study (ICS).

\section{Material and Methods}

\section{The Population and Data Collection}

This was a nested case-control study within the ICS. The ICS is an ongoing longitudinal population-based study of 6504 adults aged 35 and older at baseline, living in urban and rural (27.5\%) areas from three counties in central Iran [13]. Participants were selected through multistage random sampling from January 2 to September 28, 2001. Details of the sampling method are described in a previous publication $[13,14]$. Ethical approval was obtained from the Ethics Committee of Isfahan Cardiovascular Research Institute, a WHO collaborating center. Written informed consents were obtained from each subject. After the baseline assessment, followup of the participants was carried out every 2 years by telephone or in-person interview, physical and biochemical measurements. The interview and attendance to clinical examination response rate were $98 \%$ and $95 \%$ respectively [14]. Blood pressure, fasting blood sugar, lipid profile tests and anthropometric parameters were measured following standard protocols [14,15]. Among anti-hypertension drugs used by some subjects, beta adrenergic blocker (metoprolol, atenolol, propranolol, carvedilol and timolol), calcium channel blocker (verapamil and diltiazem), digoxin, and amiodarone were defined as heart rate-lowering drugs. The follow up period for this survey was the first seven years of ICS. Ischemic Heart Diseases (IHD) including Acute Myocardial Infarction (AMI) and Unstable Angina (UA), and stroke were defined as CVEs. Thirty minute or more typical chest pain with ST elevation more than 0.1 $\mathrm{mV}$ in at least 2 adjacent ECG leads and increase in cardiac troponin or creatine kinase were AMI definition criteria [16]. UA was defined as typical crescendo and severe chest discomfort lasting more than 20 minute preceding hospitalization with or with ECG change [17]. Stroke was explored as a rapid-onset vascular origin focal neurological defects in last 24 hour. Fatal Myocardial infarction and stroke were categorized in cardiovascular mortality. Death within one hour of onset, a witnessed cardiac arrest, or abrupt collapse not preceded by more than one hour of symptoms were SCD criteria. The reported events were re-checked and reviewed within Isfahan cardiovascular research institute by known cardiologists and neurologists monthly [14]. The control group were selected among subjects without the aforementioned events but were matched with the case group on follow-up time (density sampling) to make time at risk similar between each pair. For each case, the controls were chosen randomly from those members of the study who were at risk at the failure time (event date). In other words, the resulting case-control sample was matched with respect to the time scale used for survival analysis.

\section{PR and QTC Interval}

PR and QTC interval was measured using baseline standard 12lead ECG (on average, 6 beats). PR interval were identified as the interval from the onset of the P-wave to the end of the PR segment, and measured from the bipolar limb leads (like lead D2) in which the interval was longest and more accurate. PR interval > $200 \mathrm{msec}$ is considered as prolonged. The QTC interval is defined from the start of the QRS complex to the end of the T-wave with adjustment for heart rate by Bazett formula (QTC= QT $/ \sqrt{R R})$. The American Heart Association (AHA), the American College of Cardiology (ACC) and other professional organization has suggested that the upper limit for QTC be set at 460mesc for women $450 \mathrm{msec}$ for men [18]. Intervals were calculated by two cardiologists in two or three leads (D2, V3 and/or V5) and their mean value was calculated for each subject.

\section{Statistical Analysis}

All numerical data were presented as mean \pm standard deviation. Categorical factors were reported as number (percentage). A Chisquare test was designed to analyze categorical data and analysis of variance (ANOVA) tests was used for differences between the means. The logistic regression was used to estimate odds ratios, which are unbiased estimates of incidence rate ratios in incidence density sampling independent of any assumption [19]. Conditional logistic regression was employed using incident cardiovascular events and mortality as dependent variables and PR and QTC intervals as independent variable. Analysis was adjusted for age, age and sex, heart rate-lowering drugs and traditional CVD risk factors (multiple) for each of the dependent variables. Statistical procedure was done by Statistical Program for Social Sciences Software (SPSS) version 23. All differences were considered as statistically significant at $P$ value less than 0.050 . 


\section{Results}

We followed the 6054 subjects, aged $\geq 35$ years and without history of CVEs from the ICS during median 6.8 years. Totally 427 CVEs occurred (229 in men), including 89 (20.8\%) AMI, 193 (45.1\%) UA, 91 (21.3\%) stroke and 54 (12.6\%) SCD. Forty deceased participants with unknown diagnosis, classified in case group firstly ( $n=467$ ). ECG records of 25 subjects were lost in case group and the rhythm was non-sinus in 8 participants, that all of them were excluded from the analysis. Density sampling randomly selected the same number of subjects as control group. A total of 35 subjects from the control group were duplicate and had lost ECG record. Finally, 394 participants in the case group and 432 non-duplicate participants in the control group were included in the bivariate analysis.

Table 1 shows the basic characteristics of participants. CVD risk factors including age, Diabetes Mellitus (DM), Hypertension (HTN), dyslipidemia (except HDL level), high waist circumstance, overweight and obesity, and metabolic syndrome were more prevalent in case group significantly $(\mathrm{P}<0.050)$. Heart rate-lowering drugs consumption was also more in case group ( $\mathrm{P}<0.001)$, that it was reasonable with respect to number of HTN cases. There was no significant difference between case and control group regarding to PR and QTC intervals ( $>$ > 0.050). The mean of PR interval in men and women was $160.17 \pm 30.31$ and $151.75 \pm 31.39$ respectively, that was statistically significant $(\mathrm{P}<0.001)$. About QTC interval, it was also longer in men group significantly (386.06 \pm 36.66 Vs. $375.18 \pm 35.96, \mathrm{P}<0.001)$. In subjects with HTN, the QTC interval was $384.08 \pm 40.68$ that in comparison to normal blood pressure participants (378.60 \pm 33.77$)$ was significantly higher $(\mathrm{P}=0.036)$. The same pattern was seen for smoking and QTC interval (387.06 \pm 35.35 Vs. $378.97 \pm 37.21, \mathrm{P}=0.044$ ). It was notable that obese participants had shorter QTC interval. Our data indicates that mean of QTC interval in high waist circumstance $(\geq 94 \mathrm{~cm}$ for men and $\geq 80 \mathrm{~cm}$ for women) subjects was $378.94 \pm 35.95$ versus $385.16 \pm$ 38.20 ( $\mathrm{P}=0.027$ ). This result was also significant for higher body mass index (BMI) (more than $25 \mathrm{~kg} / \mathrm{m} 2$ ) and QTC interval (374.60 \pm 33.91 Vs. $382.44 \pm 37.28, \mathrm{P}=0.012$ ). No statistically significant association was found between other CVD risk factors and PR and QTC intervals. Of 394 eligible participants, prolonged PR interval (PR > $200 \mathrm{msec}$ ) was present in only 9 (2.3\%) subjects. Of these patients, 3 AMI (fatal: 2, non-fatal:1), 1 stroke (fatal: 1 , non-fatal: 0), 1 SCD and 4 UA was occurred. Totally 16 (4.0 \%) cases had prolonged QTC interval within CVEs patients. The distribution was 3 AMI (fatal: 1, non-fatal: 2), 7 stroke (fatal: 2, non-fatal: 5), 3 SCD and 3 UA. There was not association between prolonged PR interval and CVEs, SCD and cardiovascular mortality in crude and all adjusted models (Table 2). The same results were seen in prolonged QTC interval and CVEs and SCD; but there was significant relationship between QTC and cardiovascular mortality in crude model, 2.98 (95\% CI: 1.16-7.66, P = 0.023). However, in adjusted models there was no significant difference (Table 2).

Table 1: Basic characteristic of participants. Numerical values are presented as Mean \pm SD.

\begin{tabular}{|c|c|c|c|}
\hline Variables & $\begin{array}{c}\text { Control Group } \\
\text { n (432) }\end{array}$ & $\begin{array}{l}\text { Case Group } \\
\text { n (394) }\end{array}$ & P-Value \\
\hline PR interval (msec) & $156.36 \pm 30.33$ & $155.72 \pm 31.98$ & 0.767 \\
\hline QT interval (msec) & $378.70 \pm 35.39$ & $383.00 \pm 38.01$ & 0.093 \\
\hline Age (year) & $51.14 \pm 12.15$ & $57.84 \pm 11.43$ & $<0.001$ \\
\hline Male gender n (\%) & $215(49.7)$ & $208(52.8)$ & 0.367 \\
\hline DM n (\%) & $50(11.5)$ & $83(21.1)$ & $<0.001$ \\
\hline FBS $(\mathrm{mg} / \mathrm{dl})$ & $90.16 \pm 36.76$ & $98.54 \pm 45.38$ & 0.003 \\
\hline HTN n $(\%)$ & $111(25.6)$ & $214(54.3)$ & $<0.001$ \\
\hline SBP (mmHg) & $120.82 \pm 20.99$ & $135.70 \pm 24.90$ & $<0.001$ \\
\hline DBP (mmHg) & $78.23 \pm 11.17$ & $84.26 \pm 13.74$ & $<0.001$ \\
\hline Dyslipidemia n (\%) & $363(84.0)$ & $364(92.3)$ & $<0.001$ \\
\hline Total cholesterol (mg/dl) & $210.74 \pm 51.13$ & $232.17 \pm 55.25$ & $<0.001$ \\
\hline Triglyceride (mg/dl) & $186.69 \pm 103.23$ & $221.95 \pm 115.80$ & $<0.001$ \\
\hline HDL-C (mg/dl) & $47.09 \pm 10.60$ & $46.49 \pm 10.39$ & 0.413 \\
\hline LDL-C (mg/dl) & $126.31 \pm 41.19$ & $141.29 \pm 45.91$ & $<0.001$ \\
\hline Waist circumstance $(\mathrm{cm})$ & $93.60 \pm 12.87$ & $97.59 \pm 12.77$ & $<0.001$ \\
\hline BMI (kg/m2) & $26.07 \pm 4.18$ & $27.59 \pm 4.79$ & $<0.001$ \\
\hline Normal (19-24.9 kg/m2) & $185(42.8)$ & $121(30.7)$ & \\
\hline Overweight (25-29.9 kg/m2) & $170(39.3)$ & $171(43.4)$ & -0001 \\
\hline Obese ( $\geq 30$ kg/m2) & 77 (17.8) & $102(25.9)$ & $<0.001$ \\
\hline
\end{tabular}




\begin{tabular}{|c|c|c|c|}
\hline Smoking & $73(16.9)$ & $70(17.8)$ & 0.231 \\
Current smoker n (\%) & $23(5.3)$ & $32(8.1)$ & $292(74.0)$ \\
Former smoker n (\%) & $336(77.8)$ & $219(55.6)$ & $<0.001$ \\
\hline Never smoker n (\%) & $134(30.9)$ & $80(20.3)$ & $<0.001$ \\
\hline Metabolic syndrome n (\%) & $24(5.5)$ & \\
\hline Heart rate-lowering drugs n (\%)
\end{tabular}

Note: Diabetes Mellitus (DM) : Fasting Blood Sugar (FBS) $\geq 126 \mathrm{mg} / \mathrm{dl}$ or 2-hour post prandial glucose $\geq 200 \mathrm{mg} / \mathrm{dl}$ or receiving anti-diabetic agents; Hypertension (HTN) : systolic blood pressure $\geq 140 \mathrm{mmHg}$, diastolic blood pressure $\geq 90 \mathrm{mmHg}$ or current treatment for hypertension; Dyslipidemia categorized as one of the following: Total Cholesterol (TC) $\geq 200 \mathrm{mg} / \mathrm{dl}$ or triglyceride (TG) $\geq 150 \mathrm{mg} / \mathrm{dl}$ or High Density Lipoprotein Cholesterols (HDL-C) $<40 \mathrm{mg} / \mathrm{dl}$ for men and $<50 \mathrm{mg} / \mathrm{dl}$ for women and low density lipoprotein cholesterol $\geq 130 \mathrm{mg} / \mathrm{dl}$; According to the updated Adult Treatment Panel III guideline of the National Cholesterol Education Program definition, metabolic syndrome defriend as the presence of 3 or more of the following components: 1) serum Triglycerides (TG) $\geq 150 \mathrm{mg} / \mathrm{dl}$; 2) High-Density Lipoprotein-Cholesterol (HDL-C) $<40 \mathrm{mg} / \mathrm{dl}$ for men and $<50 \mathrm{mg} / \mathrm{dl}$ for women; 3 ) glucose $\geq 100 \mathrm{mg} / \mathrm{dl}$ fasting or on treatment; 4) Blood Pressure (BP) $\geq 130 / 85 \mathrm{mmHg}$ or antihypertensive medication use, and 5) waist circumference $\geq 102 \mathrm{~cm}$ in men and $\geq 88 \mathrm{~cm}$ in women.

Table 2: Unadjusted and adjusted odds ratios for cardiovascular events and mortality associated with prolonged PR and QT interval.

\begin{tabular}{|c|c|c|}
\hline Variable & $\begin{array}{c}\dagger \text { Prolonged PR Interval } \\
\text { n (21) }\end{array}$ & $\begin{array}{c}\ddagger \text { Prolonged QT Interval } \\
\text { n (26) }\end{array}$ \\
\hline Mean \pm SD & $231.00 \pm 18.52$ & $485.18 \pm 15.28$ \\
\hline Cardiovascular events n (\%) & $9(42.8)$ & $16(61.5)$ \\
\hline Crude OR $(95 \% \mathrm{CI})$ & $0.82(0.34-1.96)$ & $1.79(0.80-3.99)$ \\
\hline Age adjusted OR $(95 \% \mathrm{CI})$ & $0.56(0.22-1.41)$ & $1.21(0.52-2.79)$ \\
\hline Age and sex adjusted OR (95\% CI) & $0.55(0.22-1.38)$ & $1.19(0.51-2.76)$ \\
\hline Heart rate-lowering drug adjusted OR (95\% CI) & $0.62(0.24-1.58)$ & $1.21(0.51-2.85)$ \\
\hline Multivariate adjusted OR (95\% CI)\# & $0.41(0.14-1.15)$ & $1.23(0.48-3.12)$ \\
\hline Sudden Cardiac Death n (\%) & $1(4.8)$ & $3(11.5)$ \\
\hline Crude OR $(95 \%$ CI) & $0.79(0.10-6.00)$ & $2.13(0.61-7.37)$ \\
\hline Age adjusted OR $(95 \% \mathrm{CI})$ & $0.52(0.06-4.10)$ & $1.35(0.38-4.83)$ \\
\hline Age and sex adjusted OR (95\% CI) & $0.46(0.05-3.63)$ & $1.28(0.35-4.61)$ \\
\hline Heart rate-lowering drug adjusted OR $(95 \% \mathrm{CI})$ & $0.69(0.09-5.37)$ & $1.77(0.49-6.32)$ \\
\hline Multivariate adjusted OR (95\% CI) & $0.38(0.04-3.17)$ & $1.26(0.33-4.78)$ \\
\hline Cardiovascular Mortality n (\%) & $4(19.0)$ & $6(23.0)$ \\
\hline Crude OR $(95 \% \mathrm{CI})$ & $2.26(0.74-6.88)$ & $2.98(1.16-7.66)^{*}$ \\
\hline Age adjusted OR $(95 \% \mathrm{CI})$ & $1.51(0.47-4.83)$ & $1.87(0.70-5.00)$ \\
\hline Age and sex adjusted OR (95\% CI) & $1.40(0.43-4.52)$ & $1.81(0.67-4.87)$ \\
\hline Heart rate-lowering drug adjusted OR (95\% CI) & $1.77(0.55-5.65)$ & $1.94(0.72-5.27)$ \\
\hline Multivariate adjusted OR (95\% CI) & $0.99(0.27-3.59)$ & $1.43(0.49-4.18)$ \\
\hline
\end{tabular}

Note: † Prolonged PR: $\geq 200 \mathrm{msec}$.

‡ Prolonged QTC $: \geq 450 \mathrm{msec}$ in men, $\geq 460 \mathrm{msec}$ in women.

\# Multivariate adjusted: adjusted for age, sex, heart rate lowering drugs, DM, HTN, dyslipidemia, smoking, central obesity (waist circumstance) and metabolic syndrome.

*P-values less than 0.05 .

\section{Discussion}

Finding of this case-nested control study in Iranian adults, indicate that prolongation of PR and QTC intervals are not associated with CVEs, SCD and cardiovascular mortality. Our discussion can be divided into two parts. The first part is about
PR interval. In this regard, a large cohort study (10785 cases and thirty years follow up) was conducted by Aro et al. in Finland. They indicated that there was no association between prolonged PR and increase in cardiovascular and all-cause mortality, coronary artery disease related hospitalization, heart failure, Atrial Fibrillation 
(AF), or stroke in crude and multivariate adjustment analysis [20]. Cheng et al. in a community based cohort study in Framingham Heart Study reported that there was no relation between baseline PR and incidence of coronary heart disease events. However, they reported that PR prolongation is associated with increase in allcause mortality, AF and pacemaker implantation [4]. In another large study between 1989 to 2010 at Duke University Medical Center, Holmqvist et al. evaluated the association between the PR interval and the cardiovascular outcomes in 9637 patients. They indicated PR prolongation had not significant correlation with poor outcomes in coronary artery disease patient [21]. Our findings were in line with these studies regarding to CVEs and cardiovascular mortality. In contrast to these results, some studies have provided somewhat contradictory findings [22,23]. Chan et al. showed that PR prolongation strongly predicts new-onset MI, stroke and cardiovascular mortalities as well as cardiovascular endpoints such as ischemic cardiomyopathies [24]. A greater incidence of total death or all-cause mortality in subjects with prolonged PR can be attributed to older age and their comorbidity [4]. Like previous studies, our study also showed that mean PR interval was significantly longer in men than in women [20]. Overall, based on previous studies and our study, PR prolongation has no independent and strong association with CVEs and mortality and more prone to induce supraventricular arrhythmias especially AF [4,25].

The second part of this paper is related to QTC interval and its predictive status on CVEs and mortality. Straus et al. in a prospective population based cohort study indicated that prolonged QTC interval was associated with a more than two-fold increased risk of sudden cardiac death as an independent risk factor [26]. In another population-based cohort study by Dekker et al. reported that healthy black and white men and women with QTC prolongation are at increased risk of coronary heart disease and mortality independently [10]. Meta-analysis by Zhang et al. also revealed the associations between prolonged QTC interval and increased risk of total cardiovascular mortality and SCD [9]. On the whole, most studies announced prolonged QTC interval is predictive to coronary artery disease and CVD mortality [7-10,26].

The mechanism linking prolongation of QTC interval and higher risk of CVD and mortality has been proposed to be the effect of inflammation, ventricular electrical instability, dispersion of repolarization and higher prevalence of traditional metabolic risk factors $[26,27]$. In contrast to these findings, in our paper and some other studies prolonged QTC was not associated with coronary artery disease, cardiovascular mortality and SCD [11]. The reason for this difference is difficult to explain; but perhaps the variety in races and populations can be explaining the differences in the incidence of CVD risk factors and CVEs [11-12]. On the other hands, low number of CVEs during the follow up period in keeping with little ECG changes especially QTC interval prolongation can describe these differences between our results and other studies. These mentioned as major limitations of this study.

\section{Conclusion}

In conclusion, our findings indicate that prolonged PR and QTC intervals are not associated with an increased risk of CVEs and cardiovascular mortality in Iranian adult population.

\section{Acknowledgment}

The authors would like to thank Minoo Dianatkhah for helping with statistical analysis. This project would not have succeeded without the sincere efforts of the ICS staffs, especially Mansoureh Boshtam. We would also like to express our thanks to our field managers Dr Yahya Zhand (Arak), Hossein Balouchi (Isfahan) and Ahmadreza Ghasemi (Najafabad), who assisted us in administering the project.

\section{Conflict of Interest}

none declared.

\section{References}

1. Greenland P, Xie X, Liu K, Colangelo L, Liao Y, et al. (2003) Impact of minor electrocardiographic ST-segment and/or T-wave abnormalities on cardiovascular mortality during long-term follow-up. Am J Cardiol 91(9): 1068-1074.

2. Ashley EA, Raxwal VK, Froelicher VF (2000) The prevalence and prognostic significance of electrocardiographic abnormalities. Curr Probl Cardiol 25(1): 1-72.

3. Daviglus ML, Liao Y, Greenland P, Dyer AR, Liu K, et al. (1999) Association of nonspecific minor ST-T abnormalities with cardiovascular mortality: The Chicago Western Electric Study. JAMA 281(6): 530-536.

4. Cheng S, Keyes MJ, Larson MG, Mc Cabe EL, Newton-Cheh C, et al. (2009) Long-term outcomes in individuals with prolonged PRinterval or firstdegree atrioventricular block. JAMA 301(24): 2571-2577.

5. Magnani JW, Johnson VM, Sullivan LM, Gorodeski EZ, Schnabel RB, et al. (2011) P wave duration and risk of longitudinal atrial fibrillation in persons $\geq 60$ years old (from the Framingham Heart Study). Am J Cardiol 107(6): 917-921.

6. Sauer AJ, Moss AJ, Mc Nitt S, Peterson DR, Zareba W, et al. (2007) Long QT syndrome in adults. J Am Coll Cardiol 49(3): 329-337.

7. Montanez A, Ruskin JN, Hebert PR, Lamas GA, Hennekens CH (2004) Prolonged QTc interval and risksof total and cardiovascular mortality and sudden death in the general population: A review and qualitative overview of the prospective cohort studies. Arch Intern Med 164(9): 943-948.

8. Robbins J, Nelson JC, Rautaharju PM, Gottdiener IS (2003) The association between the length of the QT interval and mortality in the cardiovascular health study. Am J Med 115(9): 689-694.

9. Zhang Y, Post WS, Blasco-Colmenares E, Dalal D, Tomaselli GF, et al. (2011) Electrocardiographic QT interval and mortality: a meta-analysis. Epidemiolog 22(5): 660-670.

10. Dekker JM, Crow RS, Hannan PJ, Schouten EG, Folsom AR (2004) Heart rate-corrected QT interval prolongation predicts risk of coronary heart disease in black and white middle-aged men and women: The ARIC study. J Am Coll Cardiol 43(4): 565-571. 
11. Machado DB, Crow RS, Boland LL, Hannan PJ, Taylor HA Jr, et al. (2006) Electrocardiographic findings and incident coronary heart disease among participants in the Atherosclerosis Risk in Communities (ARIC) study. Am J Cardiol 97(8): 1176-1181.

12. Crook ED, Clark BL, Bradford ST, Golden K, Calvin R, et al. (2003) From 1960s Evans County, Georgia to present-day Jackson, Mississippi: an exploration of the evolution of cardiovascular disease in African Americans. Am J Med Sci 325(6): 307-314.

13. Sarraf-Zadegan N, Sadri G, Malek AH, Baghaei M, Mohammadi FN, et al. (2003) Isfahan Healthy Heart Programme: a comprehensive integrated community-based programme for cardiovascular disease prevention and control. Design, methods and initial experience. Acta Cardiol 58(4): 309-320.

14. Sarrafzadegan N, Talaei M, Sadeghi M, Kelishadi R, Oveisgharan S, et al. (2011) The Isfahan cohort study: Rationale, methods and main findings. J Hum Hypertens 25(9): 545-553.

15. Grundy SM, Cleeman JI, Daniels SR, Donato KA, Eckel RH, et al. (2005) Diagnosis and management of the metabolic syndrome. An American heart Association/National heart, Lung, and blood Institute Scientific statement. Executive summary. Cardiol Rev 13(6): 322-327.

16. Luepker RV, Apple FS, Christenson RH, Crow RS, Fortmann SP, et al. (2003) Case definitions for acute coronary heart disease in epidemiology and clinical research studies: A statement from the AHA Council on Epidemiology and Prevention; AHA Statistics Committee; World Heart Federation Council on Epidemiology and Prevention; the European Society of Cardiology Working Group on Epidemiology and Prevention; Centers for Disease Control and Prevention; and the National Heart, Lung, and Blood Institute. Circulation 108(20): 2543-2549.

17. Braunwald E, Antman EM, Beasley JW, Califf RM, Cheitlin MD, et al (2002) ACC/AHA guideline update for the management of patients with unstable angina and non-ST-segment elevation myocardial infarction-2002: Summary article: A report of the American College of Cardiology/American Heart Association Task Force on Practice Guidelines (Committee on the Management of Patients With Unstable Angina). Circulation 106(14): 1893-1900.

18. Rautaharju PM, Surawicz B, Gettes LS, Bailey JJ, Childers R, et al. (2009) AHA/ACCF/HRS recommendations for the standardization and interpretation of the electrocardiogram: part IV: The ST segment, $\mathrm{T}$ and $\mathrm{U}$ waves, and the QT interval: a scientific statement from the

\section{ISSN: 2574-1241}

\section{DOI: 10.26717/BJSTR.2020.29.004858}

Masoumeh Sadeghi. Biomed J Sci \& Tech Res

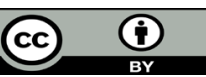

This work is licensed under Creative Commons Attribution 4.0 License

Submission Link: https://biomedres.us/submit-manuscript.php
American Heart Association Electrocardiography and Arrhythmias Committee, Council on Clinical Cardiology; the American College of Cardiology Foundation; and the Heart Rhythm Society. Endorsed by the International Society for Computerized Electrocardiology. J Am Coll Cardiol 53(11): 982-991.

19. Knol MJ, Vandenbroucke JP, Scott P, Egger M (2008) What do case-control studies estimate? Survey of methods and assumptions in published case-control research. Am J Epidemiol 168(9): 1073-1081.

20. Aro AL, Anttonen O, Kerola T, Junttila MJ, Tikkanen JT, et al. (2014) Prognostic significance of prolonged PR interval in the general population. Eur Heart J 35(2): 123-129.

21. Holmqvist F, Thomas KL, Broderick S, Ersbøll, M, Singh D, et al. (2015) Clinical outcome as a function of the PR-interval-there is virtue in moderation: Data from the Duke Databank for Cardiovascular Disease. Europace 17(6): 978-985

22. Blackburn H, Taylor HL, Keys A (1970) Coronary heart disease in seven countries. XVI. The electrocardiogram in prediction of five-year coronary heart disease incidence among men aged forty through fiftynine. Circulation 41: I154- I161.

23. Erikssen J, Otterstad JE (1984) Natural course of a prolonged PR interval and the relation between PR and incidence of coronary heart disease. A 7-year follow-up study of 1832 apparently healthy men aged 40-59 years. Clin Cardiol 7(1): 6-13.

24. Chan YH, Hai JJ, Lau KK, Li SW, Lau CP, et al. (2017) PR interval prolongation in coronary patients or risk equivalent: Excess risk of ischemic stroke and vascular pathophysiological insights. BMC Cardiovasc Disord 17(1): 233.

25. Magnani JW, Wang N, Nelson KP, Connelly S, Deo R, et al. (2013) Electrocardiographic PR interval and adverse outcomes in older adults: the Health, Aging, and Body Composition study. Circ Arrhythm Electrophysiol 6(1): 84-90.

26. Straus SM, Kors JA, De Bruin ML, Van Der Hooft CS, Hofman A, et al. (2006) Prolonged QTc interval and risk of sudden cardiac death in a population of older adults. J Am Coll Cardiol 47(2): 362-367.

27. Medenwald D, Kors JA, Loppnow H, Thiery J, Kluttig A, et al. (2014) Inflammation and prolonged QT time: results from the Cardiovascular Disease, Living and Ageing in Halle (CARLA) study. PLoS One 9(4): e95994.

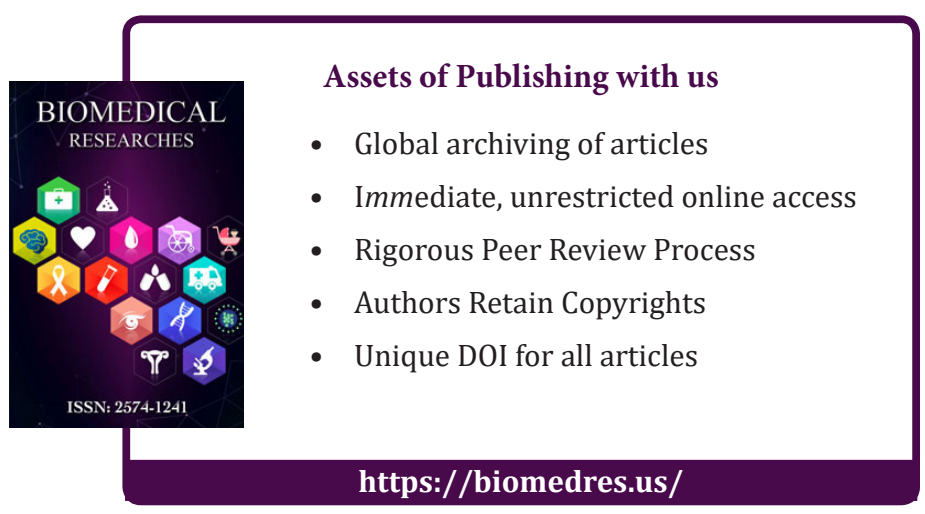

